\title{
Avaliação da dosagem de materiais carbonáceos em pelotas de minério de ferro sobre sua resistência física
}

\author{
Morbelli, B. A. P. ${ }^{1 *}$ \\ 1 Programa de Graduação em Engenharia Química, Universidade Vila Velha, Vila Velha, ES, Brasil.
}

*e-mail: breno.morbelli@hotmail.com

\begin{abstract}
Resumo
Nas usinas de pelotização de minério de ferro ocorre a adição de insumos na etapa de mistura. As pelotas de minério de ferro adquirem características físicas, químicas e metalúrgicas necessárias para resistirem às etapas subsequentes até o carregamento do produto. O carvão e o coque dosados nas pelotas cruas de minério de ferro melhoram a qualidade das pelotas, uma vez que o processo de queima se torna mais homogêneo devido a melhor transferência de calor. No entanto, um dos grandes problemas da adição exagerada destes insumos à composição da pelota de minério de ferro é a formação da estrutura duplex no interior da pelota, reduzindo a qualidade física do produto final e gerando finos nas etapas seguintes de transporte e carregamento. Desta forma, foram produzidas pelotas em Pot Grate e avaliadas quanto à sua qualidade física tendo como variável a dosagem de carbono fixo em três níveis $(0,7 \%, 1,0 \%$ e 1,3\%). O estudo mostrou que os melhores índices de qualidade física (índice de tamboramento e compressão) foram obtidos para menores dosagens de carbono fixo $(0,7 \%)$.
\end{abstract}

\begin{abstract}
In the iron pellet plants additives are used in the mixing line. Iron ore pellets acquire physical, chemical and metallurgical properties to withstand the subsequent steps up to the loading of the product. Coal and coke added in green iron ore pellets improve their quality, mainly because the burning process is more homogeneous due to better heat transfer. However, one of the major problems of excessive addition of solid fuels to the composition of the iron ore pellet is the formation of a duplex structure within the pellets, thereby reducing the physical quality of the final product and generating fine in the following stage of loading and shipping. Therefore, it is necessary to find an optimal dosage of coke or coal to the pellets in order to improve their physical and metallurgical qualities. Thus, pellets were produced in Pot Grate and evaluated for their physical quality, having as a variable the fixed carbon in three levels $(0.7 \%, 1.0 \%$ and $1.3 \%$ ). The study showed that the best physical quality values (tumbler index and cold compression strength) were obtained for lower fixed carbon dosages $(0.7 \%)$.
\end{abstract}

Keywords (Palavras chaves): Iron ore pellet. Coal addition. Metallurgical properties. Compressive strength 


\section{SEMANA DE ENGENHARIA QUÍMICA UFES}

\section{Introdução}

O processo de pelotização é um meio de aglomerar finos de minério de ferro, transformando-as em pelotas. As pelotas, após o devido tratamento térmico, possuem propriedades físicas e metalúrgicas importantes para os processos siderúrgicos, tanto para alto forno quanto para redução direta [1].

De acordo com a literatura [2], [3], diversas variáveis no processo de pelotização influenciam nas propriedades físicas e metalúrgicas das pelotas queimadas. Dentre estas influências, podemos citar a adição de materiais carbonáceos tais como carvão antracito e coque.

Antes da grande crise do petróleo na década de 70 , óleo e gás natural eram os principais combustíveis utilizados nos fornos de endurecimento de pelotas de minério de ferro. Desde então, a adição de coque e carvão nas pelotas cruas, principalmente para minérios hematíticos, tornou-se rotina para os produtores de pelotas [4].

O preço atual do gás natural e do óleo justifica uma maior adição de combustíveis sólidos. No entanto, a dosagem excessiva de carbono fixo às pelotas cruas hematíticas pode acarretar baixa resistência à compressão das pelotas queimadas [5].

Neste contexto, objetiva-se estudar em escala piloto uma quantidade ideal a ser dosada de materiais carbonáceos às pelotas cruas, a fim de garantir suas qualidades físicas.

\section{Materiais e métodos}

Um experimento pode ser determinado como um teste ou uma bateria de testes nos quais são realizadas mudanças propositais nas variáveis da entrada de um processo ou sistema, de modo que possam ser observadas e identificadas as razões para alterações na resposta de saída [6].

Abaixo, são definidos alguns conceitos relacionados ao planejamento de experimentos [7]:
- Fatores: são as variáveis independentes ou entradas de processo que serão analisadas nos experimentos, e cujo efeito se quer testar;

- Níveis: cada um dos possíveis valores que um fator pode assumir no experimento;

- Tratamento: é um nível único assinalado para um fator durante um experimento;

- Resposta: é a variável dependente do experimento ou saída do processo.

Usando planejamentos experimentais baseados em princípios estatísticos, é possível extrair do sistema em estudo a maior quantidade de informação útil, fazendo um número mínimo de experimentos [8].

Logo, o planejamento do experimento e a análise estatística dos dados devem estar presentes em qualquer estudo experimental, sendo que estes dois aspectos estão estreitamente associados, já que a técnica de análise depende do planejamento utilizado [9].

O estudo proposto visa, entre outros pontos, correlacionar 0 efeito da adição de materiais carbonáceos, na etapa da mistura, com a qualidade física das pelotas de minério de ferro. Foram escolhidos três níveis de dosagem de carbono fixo nas pelotas cruas $(0,7 \%, 1,0 \%$ e $1,3 \%)$ que foram feitas tanto para carvão quanto para coque, enquanto mantem-se fixa a quantidade de pellet feed, a umidade do pellet feed, calcário, bentonita, além dos perfis de queima para a produção das pelotas.

A partir dos resultados das caracterizações químicas do carvão e do coque, foi feito um balanço de massa para determinar a quantidade desses materiais junto ao pellet feed, calcário e bentonita de acordo com os níveis de \% de carbono fixo para preparação das misturas. As misturas foram preparadas em um misturador consolidando-se a umidade do pellet feed em $10,2 \%$, para evitar o efeito desta variável sobre os resultados finais. Após a preparação, cada mistura foi pelotizada em um disco piloto de 1 metro de diâmetro visando obter pelotas cruas distribuídas igualmente na 
granulometria entre 16,0 e $12,5 \mathrm{~mm}$ e 12,5 e $9,0 \mathrm{~mm}$.

A tabela 1 detalha o planejamento do experimento.

Tabela 1: Planejamento do Experimento.

\begin{tabular}{cccc}
\hline Material & \multicolumn{3}{c}{$\%$ Carbono Fixo } \\
\hline Carvão & 0,7 & 1,0 & 1,3 \\
\hline Coque & 0,7 & 1,0 & 1,3
\end{tabular}

As variáveis de resposta deste experimento foram fornecidas através de ensaios realizados em laboratório. As variáveis de respostas determinadas foram o índice de tamboramento (\%), a resistência à compressão (Kgf) e quantidade de $\mathrm{FeO}$ na pelota queimada (\%).

\subsection{Teste de resistência à compressão}

Para a determinação da resistência à compressão a frio de pelotas, foi utilizado o padrão mundial ISO 4700 .

Segundo este padrão, 100 pelotas das amostras são individualmente colocadas entre duas placas paralelas e submetidas à ação de força compressiva uniaxial, a uma taxa específica (10 a $20 \mathrm{~mm} / \mathrm{min}$ ), até a sua ruptura. $\mathrm{O}$ valor médio dos ensaios é reportado como o resultado final, acompanhado do desvio padrão, dos valores máximo e mínimo e da porcentagem do número de pelotas com força de ruptura menor que $200 \mathrm{Kgf}$.

\subsection{Teste de tamboramento das pelotas queimadas}

O ensaio de tamboramento foi utilizado para avaliar a resistência ao atrito durante transporte, manuseio e ao próprio atrito entre as pelotas durante a descida da carga nos reatores.

Para a determinação do índice de tamboramento e abrasão é utilizado o padrão ISO 3271 - Determination of Tumble Strength. O teste consiste em colocar uma massa de $15 \mathrm{~kg}$ da amostra de pelotas, de granulometria entre $6,3 \mathrm{~mm}$ e $19,0 \mathrm{~mm}$, em um tambor de abrasão e submetê-las a 200 rotações, a uma velocidade de rotação de 25 RPM. O resultado de tamboramento é expresso como o percentual de material retido na peneira de $6,3 \mathrm{~mm}$, e a abrasão é o percentual passante na peneira de $0,5 \mathrm{~mm}$.

\subsection{Análise química das pelotas queimadas}

As análises químicas de ferro total (FeT) e de óxido ferroso $(\mathrm{FeO})$ foram realizadas através de um titulador potenciométrico automático da marca Metrohm modelo 906 Titrando seguindo a norma ISO 2597.

\section{Resultados e discussões}

Para todas as variáveis de resposta definidas, foram feitos testes da análise de variância (ANOVA) com o auxílio do software estatístico Minitab.

Neste capítulo, descrevem-se os efeitos apresentados por cada um dos níveis do fator nas variáveis de resposta abordadas no estudo.

\subsection{Efeito sobre a resistência à compressão}

Os resultados da análise de variância para a resistência à compressão são mostrados na Figura 1.

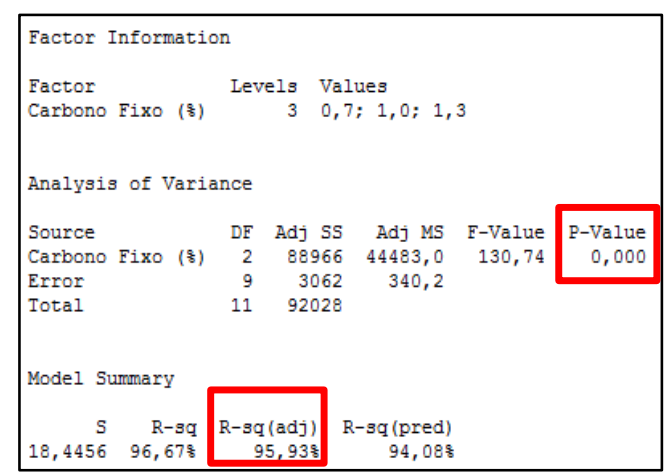

Figura 1: ANOVA para resistência à compressão.

Os resultados da análise de variância mostram que há significância entre os resultados de resistência à compressão e a variação da dosagem de carbono fixo. Esta afirmação é validada pelo $p$-valor encontrado menor que 0,05 , com um poder de explicação do resultado de $95,93 \%$ (R quadrado ajustado).

Como mostrado na Figura 2, a resistência à compressão apresenta o ponto de máximo para teor de carbono fixo de 0,7\%. Para valores acima de 0,7\%, nota-se queda no valor de resistência à compressão. Percebe-se também que a média do índice de tamboramento é maior quando se dosa coque do que quando se dosa carvão. 


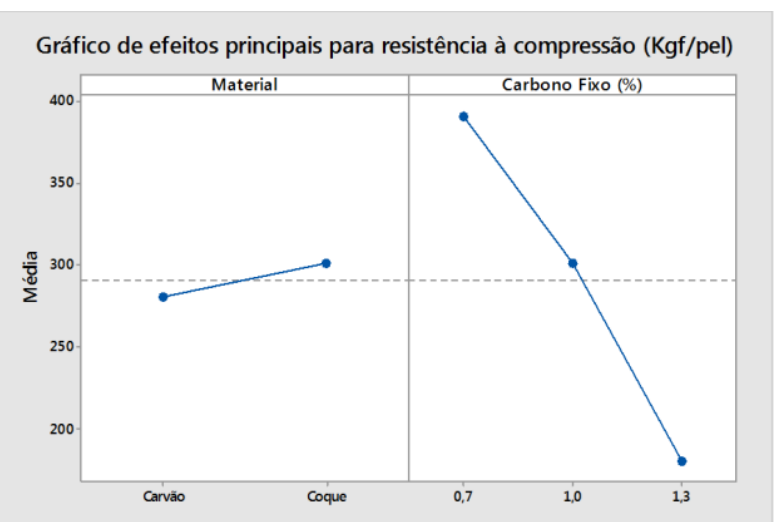

Figura 2: Gráfico dos níveis do fator para a média de resistência à compressão.

O efeito da dosagem de carbono fixo na pelota crua sobre a resistência à compressão da pelota queimada está relacionado diretamente com a queima do material carbonáceo formando poros que irão depender de sua distribuição no interior da pelota.

Além disso, a elevação do carbono da pelota crua pode favorecer a formação de magnetita, com efeito negativo na resistência à compressão.

Os resultados da análise de variância para a o teor de FeO são mostrados na Figura 3.

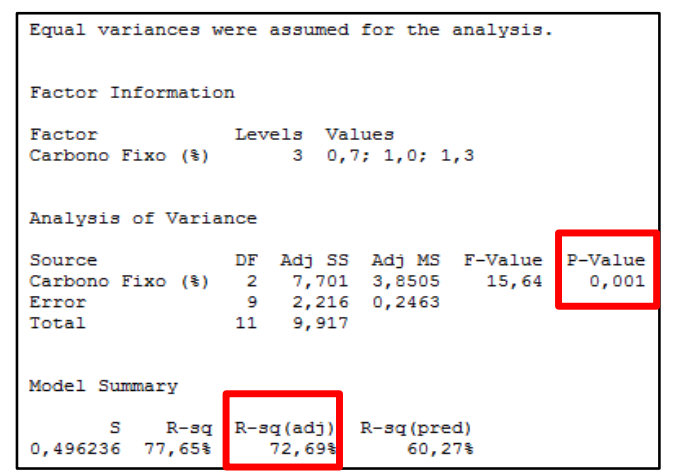

Figura 3: ANOVA para teor de $\mathrm{FeO}$.

Os resultados da análise de variância mostram que há significância entre os resultados de teor de $\mathrm{FeO}$ e a variação da dosagem de carbono fixo. Esta afirmação é validada pelo $p$-valor encontrado menor que 0,05 , com um poder de explicação do resultado de 72,69\% ( $R$ quadrado ajustado).

$\mathrm{Na}$ Figura 4, destaca-se a relação do aumento da dosagem de carbono fixo e o teor de $\mathrm{FeO}$ da pelota queimada. Como evidenciado anteriormente, o teor de
FeO na pelota queimada é uma medida indireta da quantidade de magnetita presente na pelota. Nota-se que o aumento de carbono fixo promoveu o aumento de $\mathrm{FeO}$ na pelota queimada, o que indica maior quantidade de magnetita.

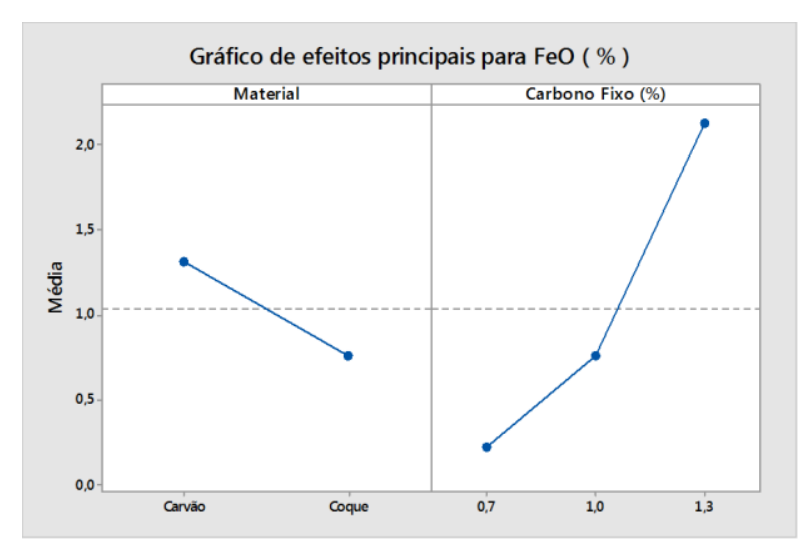

Figura 4: Gráfico dos níveis do fator para a média da quantidade de FeO.

Para uma melhor identificação da formação da magnetita, as pelotas em estudos foram conduzidas para análise em microscópio ótico. A Figura 5 abaixo mostra micrografias da região central das pelotas produzidas com aumento de 500x.

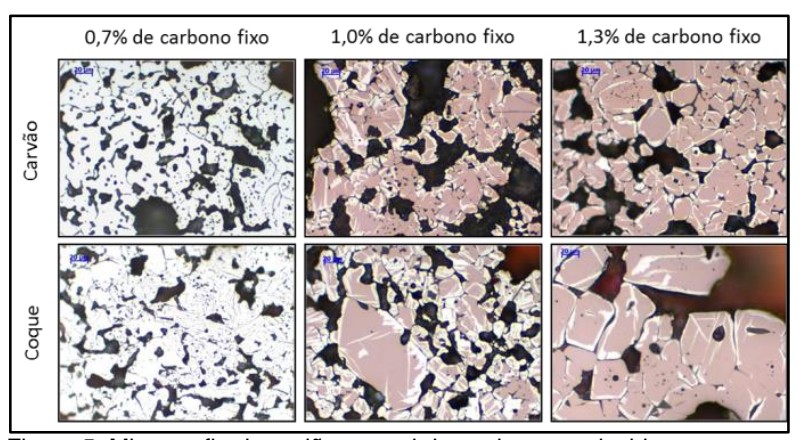

Figura 5: Micrografia da região central das pelotas produzidas.

Como mostrado acima, percebe-se claramente o aumento da quantidade de magnetita (região rosácea) na pelota queimada à medida que se eleva a dosagem de carbono fixo. Percebe-se também que o aumento do teor de carbono fixo, favoreceu o crescimento dos grãos de minério, aumentando as tensões internas e comprometendo a resistência à compressão.

\subsection{Efeito sobre o tamboramento}

Os resultados da análise de variância para o índice de tamboramento são mostrados na Figura 6. 


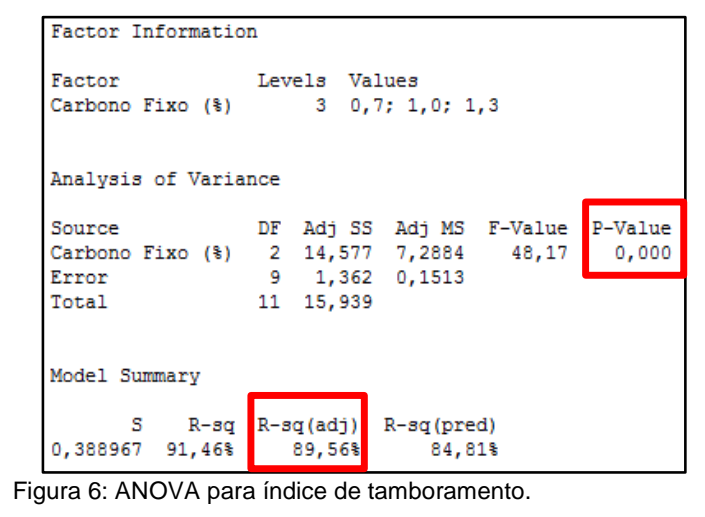

Os resultados da análise de variância mostram que há significância entre os resultados de índice de tamboramento e a variação da dosagem de carbono fixo. Esta afirmação é validada pelo $p$-valor encontrado menor que 0,05 , com um poder de explicação do resultado de $89,56 \%$ (R quadrado ajustado).

Como mostrado na Figura 7, o índice de tamboramento apresenta o ponto de máximo para teor de carbono fixo de $0,7 \%$. Para valores acima de $0,7 \%$, nota-se queda no índice de tamboramento. Percebe-se também que a média do índice de tamboramento é maior quando se dosa coque do que quando se dosa carvão.

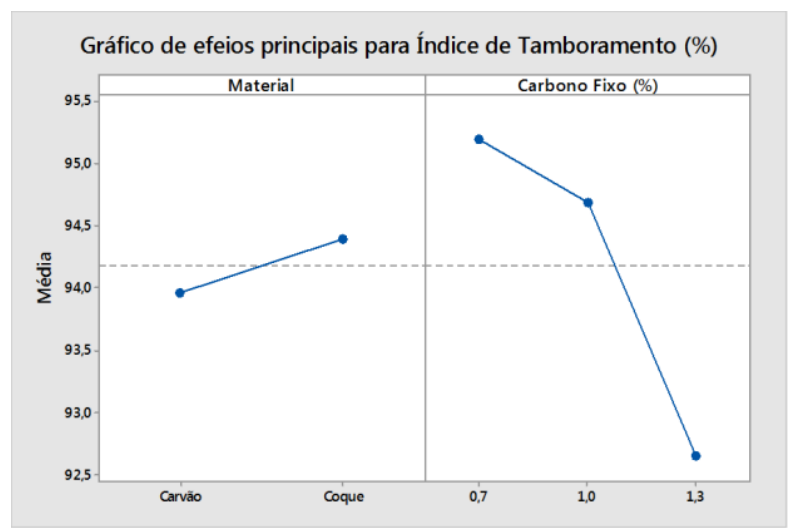

Figura 7: Gráfico dos níveis do fator para a média do índice de tamboramento,

Sabe-se que as características principais para se obter índice de tamboramento ideal para as pelotas queimadas estão relacionadas ao seu acabamento superficial, ou seja, seu comportamento no disco de pelotamento. Portanto, as pelotas com ausência de trincas e bem queimadas apresentarão melhores resultados.

Dessa maneira, o aumento do teor de carbono fixo favorece a sinterização da hematita até certa fase $(0,7$ $\%$ de carbono), a partir do valor que ocorreria prejuízo ao acabamento superficial, diminuindo o índice de tamboramento.

\section{Conclusões}

A partir da metodologia estabelecida e das variáveis testadas, verificou-se que a variação dos níveis de carbono fixo nas pelotas apresentou influência no índice de tamboramento, resistência à compressão e na quantidade de $\mathrm{FeO}$ nas pelotas;

Essa observação é confirmada ao analisar estaticamente os resultados obtidos através da análise da variância (ANOVA). Pode-se confirmar que o índice de tamboramento, resistência à compressão, e a quantidade de $\mathrm{FeO}$ nas pelotas foram influenciados significativamente ( $p$-valor $<0,05)$ pela alteração da dosagem de carbono fixo nas pelotas.

Para resistência à compressão e índice de tamboramento, a melhor faixa de trabalho de carbono fixo é de $0,7 \%$, onde as pelotas apresentam-se mais resistentes e menos degradáveis devido as melhores reações de sinterização dos grãos de hematita e de quantidade menores de $\mathrm{FeO}$, que reduz a qualidade da pelota.

As conclusões obtidas através do presente estudo podem ser estendidas para a realidade industrial do processo produtivo de pelotização.

\section{Referências}

\section{Teses ou dissertações}

[1] COSTA, R. V. P. da Otimização da resistência à compressão de pelotas de minério de ferro para redução direta pela aplicação de projeto robusto, Dissertação de mestrado, UFOP, Ouro Preto, 2008, 130p.

[2] MEYER, K. Pelletizing of Iron Ores - Springer Verlag Berlin, Heidelberg, and Verlag Stahleissen $\mathrm{mbH}$, Düsseldorf, Germany, 21-205, 1980.

[3] FONSECA, M.C. Influência da distribuição granulométrica do pellet feed no processo de aglomeração e na qualidade da pelota de minério de ferro para redução direta, Dissertação de Mestrado, REDEMAT, Ouro Preto, 2004, 259p.

[4] AUDET, A. et al. Coke addition in the iron ore pelletizing process, Combustion Canada 03, Canada, 2003. 
[5] LU, W.K. et al. Fluxed pellets with high coke breeze additions, Ironmaking Conference Proceedings, p. 3-11, 1990.

[6] CALEGARE, A. J. de A. Introdução ao delineamento de experimentos, 1. ed. São Paulo, 2001.

[7] ROTONDARO, R. G. et al. Seis sigma: estratégia gerencial para a melhoria de processos, produtos e serviços, 1. ed. São Paulo, 2002.

[8] BARROS NETO, B. de, BRUNS, R. E., SCARMINIO, I. S. Como fazer experimentos: pesquisa e desenvolvimento na ciência e na indústria, 2. ed. Campinas, 2003.

[9] WERKEMA, M. C. C., AGUIAR, S. Planejamento e análise de experimentos: como identificar as principais variáveis influentes em um processo, Belo Horizonte, 1996. 